\title{
Change of iron species and iron solubility in Asian dust during the long-range transport from western China to Japan
}

\author{
Y. Takahashi ${ }^{1}$, M. Higashi ${ }^{1}$, T. Furukawa ${ }^{1}$, and S. Mitsunobu ${ }^{2}$ \\ ${ }^{1}$ Department of Earth and Planetary Systems Science, Graduate School of Science, Hiroshima University, Higashi-Hiroshima, \\ Hiroshima 739-8526, Japan \\ ${ }^{2}$ University of Shizuoka, 52-1 Yada, Suruga-ku, Shizuoka 422-8526, Japan
}

Received: 5 May 2011 - Published in Atmos. Chem. Phys. Discuss.: 8 July 2011

Revised: 22 October 2011 - Accepted: 1 November 2011 - Published: 11 November 2011

\begin{abstract}
In the North Pacific, transport and deposition of mineral dust from Asia appear to be one of major sources of iron which can regulate growth of phytoplankton in the ocean. In this process, it is essential to identify chemical species of iron contained in Asian dust, because bioavailability of iron in the ocean is strongly influenced by the solubility of iron, which in turn is dependent on iron species in the dust. Here, we report that clay minerals (illite and chlorite) in the dusts near the source collected at Aksu (western China) can be transformed into ferrihydrite by atmospheric chemical processes during their long-range transport to eastern China (Qingdao) and Japan (Tsukuba) based on the speciation by X-ray absorption fine structure (XAFS) and other methods such as X-ray diffraction and chemical extraction. As a result, Fe molar ratio in Aksu (illite : chlorite : ferrihydrite $=70: 25: 5$ ) was changed to that in Tsukuba (illite $:$ chlorite $:$ ferrihydrite $=65: 10: 25$ ). Moreover, leaching experiments were conducted to study the change of iron solubility. It was found that the iron solubility for the dust in Tsukuba (soluble iron fraction: $11.8 \%$ and $1.10 \%$ for synthetic rain water and seawater, respectively) was larger than that in Aksu (4.1\% and $0.28 \%$, respectively), showing that iron in the dust after the transport becomes more soluble possibly due to the formation of ferrihydrite in the atmosphere. Our findings suggested that secondary formation of ferrihydrite during the transport should be considered as one of important processes in evaluating the supply of soluble iron to seawater.
\end{abstract}

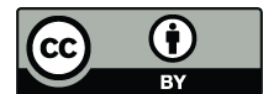

Correspondence to: Y. Takahashi (ytakaha@hiroshima-u.ac.jp)

\section{Introduction}

Iron $(\mathrm{Fe})$ is an essential micronutrient and has been identified as a limiting factor for growth of phytoplankton in highnitrate low-chlorophyll (HNLC) regions of the ocean (Martin and Fitzwater, 1988; de Baar et al., 1995; Jickells et al., 2005; Boyd and Ellwood, 2010). In the North Pacific, one of the HNLC regions, transport and deposition of mineral dust from Asia can be one of major sources of Fe (e.g., Duce and Tindale, 1991). In the atmosphere, Fe can be found and transported in a variety of chemical forms, both water-soluble and -insoluble. It is generally believed that the soluble fraction of Fe is mainly considered as bioavailable for phytoplankton (Jickells et al., 2005; Baker et al., 2006).

Overall solubility of atmospherically transported $\mathrm{Fe}$ at seawater $\mathrm{pH}$ is estimated to be $0.8-2.1 \%$ (Jickells and Spokes, 2006). However, large uncertainties exist in the estimates of bioavailable Fe deposited from the atmosphere, owing to wide range of $\mathrm{Fe}$ solubility in seawater (Mahowald, 2005). Although it has been suggested that atmospheric processes can change the solubility of $\mathrm{Fe}$ as it moves from the source to the deposition area in oceans, actual chemical processes affecting Fe species in the solid phase in the mineral dusts are not clear. For example, photo-reductive processes (Siefert et al., 1994), in-cloud processes (Desboeufs et al., 2001), and uptake of secondary acids (Zhuang et al., 1992; Meskhidze et al., 2003) can increase the solubility and bioavailability of Fe in the dust particles, which is an important pathway for the fertilization of remote oceans with subsequent climate impacts. However, change of $\mathrm{Fe}$ species during long-range transport based on actual data on the Fe species has not been widely studied up to now.

Published by Copernicus Publications on behalf of the European Geosciences Union. 
It is strongly suggested that the bioavailability of Fe is influenced by its solubility which in turn is dependent on chemical species of Fe contained in Asian dust. Thus, to accurately assess the biogeochemical impact of the atmospheric input, an attempt was made in this study to identify the Fe species and quantify each species by synchrotronbased X-ray absorption fine structure (XAFS) spectroscopy, a powerful technique used to investigate chemical speciation in aerosol samples (Takahashi et al., 2006; Higashi and Takahashi, 2009; Schroth et al., 2009; Furukawa and Takahashi, 2011). The speciation data were confirmed by Xray diffraction and chemical extraction method to identify specific phases. Moreover, leaching experiments were conducted for the natural Asian dust samples with thorough information of Fe species contained in the dust, by which it was possible to show the relationship between $\mathrm{Fe}$ species and its solubility.

In this study, we focus on the Asian dust-storm because of its significance as a source of dust supplied to the North Pacific region. In the springtime, large scale dust storms frequently occur in the western China and a large amount of dusts can be transported long distances over the HNLC region of the North Pacific under the influence of westerly winds. In addition, the dusts passing through the highly populated and industrialized regions in eastern China have ample opportunity to be subject to influence of pollutants (Akimoto and Narita, 1994), which can enhance the primary productivity and $\mathrm{CO}_{2}$ uptake of the ocean, assuming that anthropogenic emission of $\mathrm{SO}_{2}$ and $\mathrm{NO}_{\mathrm{x}}$ has some effects on Fe dissolution from mineral dust (Meskhidze et al., 2003). Hence, we describe the increase of Fe solubility caused by transformation of initially stable atmospheric Fe into more soluble phase during the long-range transport from western China to Japan and subsequently discuss the anthropogenic effect on the transformation of Fe species in the dust.

\section{Experimental section}

\subsection{Sample collection and characterization}

Aerosol samples used in this study were collected at Aksu $\left(40.61^{\circ} \mathrm{N}, 80.73^{\circ} \mathrm{E}\right)$, Qingdao $\left(36.07^{\circ} \mathrm{N}, 120.33^{\circ} \mathrm{E}\right)$, and Tsukuba $\left(36.06^{\circ} \mathrm{N}, 140.14^{\circ} \mathrm{E}\right)$ as part of the Japan-China joint project, "Asian Dust Experiment on Climate Impact (ADEC)" (Table S1 in Supplement; Kanai et al., 2005; Yabuki et al., 2005; Mikami et al., 2006). From 2000 to 2005, aerosol samples were constantly collected in these sites simultaneously using both Andersen-type air samplers (AN-200, Sibata, Tokyo) and high-volume air sampler (HV1000F, Sibata, Tokyo). The Andersen-type sampler was used to obtain size-fractionated samples. The particle diameters classified by the aerodynamic diameter in the Andersen-type air sampler were as follows: $>11 \mu \mathrm{m}$ (sampling stage 0),

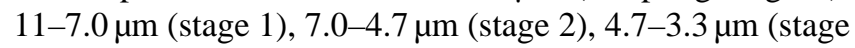

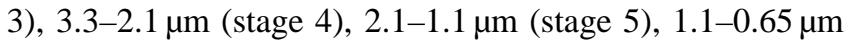
(stage 6), $0.65-0.43 \mu \mathrm{m}$ (stage 7), and $<0.43 \mu \mathrm{m}$ (backup filter). The filters used for Stage-0 to -6 were Advantec PF050 polyflon filters (Advantec, Tokyo), and those for Stage-7 and the backup filter were Tokyo Dylec 2500QAT-UP quartz filters (Dylec, Tokyo). The filters were weighed before and after the sampling with a reading precision of $10 \mu \mathrm{g}$ after being stabilized in constant humidity in a desiccator. The $\mathrm{Fe}$ signals from the both types of the filters were found to be minimal in XAFS measurement. A high-volume type air sampler was used to collect larger amount of total suspended particulate (TSP) samples, though the size was not fractionated. The samples were collected on polyflon filters at Aksu and Tsukuba, which were used to perform XRD analyses and leaching experiments. Further details about the samples employed here were described in previous studies (Kanai et al., 2005; Yabuki et al., 2005).

Various Fe compounds of analytical grade were obtained from Wako Pure Chemical Industries Ltd. or Kanto Chemical Co. Inc as reference materials (Fe(III) oxalate, Fe(III) citrate, $\mathrm{Fe}(\mathrm{III})$ sulfate, magnetite $\left(\mathrm{Fe}_{3} \mathrm{O}_{4}\right), \mathrm{FeO}$, siderite $\left(\mathrm{FeCO}_{3}\right)$, and $\mathrm{Fe}(\mathrm{II})$ sulfate). Clay minerals were received from the Source Clays Repository of the Clay Mineral Society, USA including smectite (SWy-2), illite (IMt-1), and chlorite (CCa-2). After dry sieving, the clay standards with the grain size smaller than $20 \mu \mathrm{m}$ were obtained. Minerals such as fayalite $\left(\mathrm{Fe}_{2} \mathrm{SiO}_{4}\right)$, pyrrhotite $\left(\mathrm{Fe}_{7} \mathrm{~S}_{8}\right)$, and pyrite $\left(\mathrm{FeS}_{2}\right)$ were received from Nichika Inc. (Kyoto, Japan). 2-line ferrihydrite was prepared by hydrolysis of ferric nitrate at $\mathrm{pH} 7.5$ and $20 \pm 2{ }^{\circ} \mathrm{C}$ (Schwertmann and Cornell, 2000). Goethite and hematite were also synthesized following Schwertmann and Cornell (2000). Desert sand in the Taklimakan Desert used in Chang et al. (2000) was also compared to dust source materials. Three-dimensional air mass back-trajectories were calculated at three altitudes using the Hybrid Single-Particle Lagrangian-Integrated Trajectory (HYSPLIT4) model (Draxler and Rolph, 2003).

\subsection{Chemical analyses, leaching experiments, and chemical extraction}

Bulk chemical analyses of the water-soluble components and water-insoluble components in size-fractionated aerosol samples stored under frozen conditions were conducted using a procedure reported previously (Kanai et al., 2005). For the TSP and reference materials, about $10 \mathrm{mg}$ of each sample was treated in closed Teflon (PTFE) vials and digested with $1 \mathrm{~mL}$ of $70 \% \mathrm{HClO}_{4}$ and $3 \mathrm{~mL}$ of $38 \% \mathrm{HF}$ at $180^{\circ} \mathrm{C}$ for approximately 3 days. The acids were evaporated to nearly dryness at $160^{\circ} \mathrm{C}$ from the opened vials. The residue was dissolved in $0.5 \mathrm{~mL}$ of $\mathrm{HCl}$ and $9.5 \mathrm{~mL}$ of $2 \% \mathrm{HNO}_{3}$. After digestion, the solution in the vial was transferred to a polyethylene bottle and diluted with $2 \% \mathrm{HNO}_{3}$. This solution was used for the analysis of the total Fe concentration (T-Fe) determined by ICP-AES. 
Two types of leaching experiments were conducted with TSP samples and reference materials to determine the dissolution of $\mathrm{Fe}$ in simulated rainwater and seawater. For a system simulating rainwater, a weak acid $(0.020 \mathrm{M}$ oxalic acid/ammonium oxalate, $\mathrm{pH}$ 4.7) was chosen to mimic release of $\mathrm{Fe}$ from aerosol to rainwater, where the $\mathrm{pH}$ is a median value for cloud droplets ( $\mathrm{Li}$ and Aneja, 1992). In the other system, $0.70 \mathrm{M} \mathrm{NaCl}(\mathrm{pH} 8)$ with $0.10 \mathrm{mM}$ ethylenediaminetetraacetic acid (EDTA) was used to simulate seawater condition. In our experiments, $2.1 \pm 0.2 \mathrm{mg}$ of TSP sample was mixed with $15.0 \mathrm{~g}$ of one of the two solutions written above. Dissolved Fe concentration (D-Fe) in the solution at a temperature of $20^{\circ} \mathrm{C}$ after $24 \mathrm{~h}$ was determined by ICPAES after filtration through $0.20 \mu \mathrm{m}$ membrane filter. The $\mathrm{Fe}$ solubility here is defined as the percentage of $\mathrm{Fe}$ released in the solution after $24 \mathrm{~h}$ : $\mathrm{Fe}_{\mathrm{Sol}}(\%)=(\mathrm{D}-\mathrm{Fe} / \mathrm{T}-\mathrm{Fe}) \times 100$.

Following Lafon et al. (2004), a chemical extraction experiment method was employed to confirm Fe speciation results obtained by XAFS using citrate-bicarbonate-dithionite (CBD) reagent, by which we quantified $\mathrm{Fe}$ oxides in dust samples for the TSP samples collected in Aksu and Tsukuba (the experiments were not conducted for the samples in Qingdao, since the TSP sample was not available for Qingdao). For the CBD method, about $3 \mathrm{mg}$ of samples recovered from the TSP filter by spatula were treated with CBD reagent to determine amounts of various Fe oxides including ferrihydrite, goethite, and hematite. This method was an adaptation for aerosol samples of the classical method developed for soil analysis (Mehra and Jackson, 1960). Iron leached into the solution was determined by ICP-MS (Agilent 7700) by measuring ${ }^{57} \mathrm{Fe}$ in He-collision mode to suppress the matrix effect from ${ }^{40} \mathrm{Ar}^{16} \mathrm{O}$ using high energy plasma condition $(1500 \mathrm{~W})$. This mode is effective to measure ${ }^{57} \mathrm{Fe}$ in high matrix solution such as for the CBD solution. In addition, final solution for ICP-MS measurement was diluted from the leaching solution more than a factor of 15 to reduce the matrix effect.

Another chemical extraction experiment using oxalate was conducted following Tessier et al. (1979) and LaForce and Fendorf (2000), which is more specific to less crystalline $\mathrm{Fe}$ oxides, that is ferrihydrite. This method uses oxalate solution $(0.10 \mathrm{M}$ oxalic acid/ammonium oxalate, $\mathrm{pH} 4.7)$ to extract ferrihydrite. The experimental procedure was similar to that in the CBD method except for the extraction process.

\subsection{XAFS measurements and data analysis}

Iron speciation was conducted by Fe K-edge XAFS. In our analysis, we used $\mathrm{mm}$ size $\mathrm{X}$-ray beam used for the sub $\mathrm{mg}$ aerosol particles collected on the filter, showing that $\mathrm{Fe}$ speciation data in this study are bulk analysis in our study. Iron K-edge XAFS spectra were measured at beamline BL12C at Photon Factory (PF), KEK. Incident X-rays were monochromatized with a $\mathrm{Si}(111)$ double-crystal monochromator and focused to $0.5 \times 0.5 \mathrm{~mm}^{2}$ with a bent cylindrical mirror. The samples appearing on the filter as dark spots (spot size:
$0.5-2 \mathrm{~mm}$ ) were directly exposed to the incident X-ray beam. Energy calibration was made by defining the pre-edge peak maximum of hematite fixed at $7.110 \mathrm{keV}$. The measurements were carried out at room temperature under ambient air condition. XAFS spectra of the samples were mainly recorded in fluorescence yield (FY) mode. The filter with the aerosol sample was placed at 45 degrees from the incident beam, and the fluorescent X-rays were measured with a 19 element Ge solid-state detector to obtain the spectra. One to three scans were summed to improve the signal-to-noise ratio. All the spectra were normalized to unit step in the absorption coefficient. No radiation damage was found during the data acquisition, because multiple scans gave identical spectra to one another.

Measurement of XAFS in the conversion electron yield (CEY) mode was also conducted using a CEY detector unit. The KLL Auger electrons induced by X-ray absorption were amplified by $\mathrm{He}$ gas and collected by another electrode biased at 500 V. Probing depths of Fe KLL Auger electron from selected minerals were estimated using the "universal curve" (Schroeder, 1996). Considering the particle size of mineral dust (mainly less than $10 \mu \mathrm{m}$ ), CEY-XAFS is surface sensitive with the probing depth of less than $0.30 \mu \mathrm{m}$, whereas FYXAFS can be regarded as a bulk method with that of greater than $5 \mu \mathrm{m}$. The supplement data were also obtained at beamline BL01B1 in SPring-8, which gave the identical spectra to those measured in Photon Factory.

Contribution of various $\mathrm{Fe}$ species to each sample was estimated by calculating the X-ray absorption near-edge structure (XANES) spectra of the unknown samples by those of known reference materials using the linear combination fit (LCF) technique using a XAFS software package REX2000 (Rigaku, Japan). The LCF using XANES was conducted in the energy ranges of $7.110-7.150 \mathrm{keV}$. The quality of the LCF was given by the residual value, the goodness-of-fit parameter $R$, defined by $R=\Sigma\left[I_{\exp }(E)-\right.$ $\left.I_{\text {cal }}(E)\right]^{2} / \Sigma\left[I_{\exp }(E)\right]^{2} \times 100$ where $I_{\exp }$ and $I_{\text {cal }}$ are the absorption of the experimental and calculated spectra, respectively. Precision of relative ratios of each $\mathrm{Fe}$ species determined by the LCF was estimated to be better than $3 \%$ obtained from three scans of same and different aerosol spots on filters, respectively. In addition, principle component analysis (PCA) to determine number of end members to fit the spectra was conducted by a software Athena (Ravel and Newville, 2005).

Iron speciation analysis was also conducted by similar LCF techniques employed for EXAFS in $\mathrm{k}$ space. EXAFS spectra were background-subtracted and normalized. Then, the smooth Fe K-edge absorption of free atom $\left(\mu_{0}\right)$ was removed using a spline smoothing curve. The energy unit was transformed from $\mathrm{keV}$ to $\AA^{-1}$ to produce the EXAFS function $\chi(k)$, where $k\left(\AA^{-1}\right)$ is the photoelectron wave vector. In this study, a threshold energy (energy at which $k$ equals to zero) was fixed at $7.120 \mathrm{keV}$. Subsequently, the $k^{3}$-weighted EXAFS spectra were also fitted using the LCF of reference 
spectra at a $k$ range of $1.0-10.0 \AA^{-1}$ by minimizing the residual of the fit, defined as above. The goodness of the fitting can be evaluated also by $R$ value defined as $R=\Sigma\left[k^{3} \chi_{\exp }(k)\right.$ $\left.-k^{3} \chi_{\mathrm{cal}}(k)\right]^{2} / \Sigma\left[k^{3} \chi_{\exp }(k)\right]^{2} \times 100$.

\section{Results and discussion}

\subsection{Physical and chemical characteristics of Asian dust}

In all stations, mass concentrations of aerosols with the grain size above $1 \mu \mathrm{m}$ during the dust period were much higher than those during the nondust period (August 2001 and January 2001) by factors of 16, 7.0, and 3.6 in Aksu, Qingdao, and Tsukuba, respectively (Figs. 1 and 2). In addition, mass concentrations of the aerosols decreased successively from Aksu $>$ Qingdao $>$ Tsukuba. Samples were actually collected during a "super large dust event" simultaneously observed in the three sites (Shao et al., 2003; Kanai et al., 2003, 2005), which strongly suggests that the dust particles originating in the desert area of western China were transported to Japan (Kanai et al., 2003, 2005). To identify the source of mineral dust collected in all the sampling sites, backward trajectory analysis was performed using the Hybrid Single-Particle Lagrangian-Integrated Trajectory (HYSPLIT4) model (Draxler and Rolph, 2003). Threedimensional air mass back-trajectories during the sampling period in Tsukuba revealed that air mass in the vicinity of Aksu on 19 March arrived in Qingdao and Tsukuba on 21 and 22 March, respectively (Fig. 3). The results were consistent with observations at these sites (Shao et al., 2003; Kanai et al., 2003, 2005), showing that the Taklimakan Desert in China was one of important source areas of mineral dust for the dust event transported to eastern China and Japan in March 2002. There can be various particles classified into the coarse particle fractions such as sea salt, volcanic ash, and plant particle in addition to mineral aerosols (Finlayson-Pitts and Pitts, 1999). Due to the very large scale of the dust event in the period, it is most likely that contribution of aerosols from other sources can be minor for iron supply compared with the mineral dust originating from western China. Based on these results, it is suggested that the samples collected in this study at the three sites can trace the chemical transformation of elements in Asian dust during their long-range transport from Aksu, close to the Taklimakan Desert, to Qingdao and Tsukuba. Although other source areas may also contribute to the supply of the mineral dusts, the contribution of $\mathrm{Fe}$ species from all the source areas is likely less than that from the Taklimakan Desert, which will be also discussed below.

Mass concentrations of insoluble fractions for aluminum (Al) and Fe were very high in Aksu and decreased in the order of Aksu, > Qingdao > Tsukuba; the size-distribution patterns of $\mathrm{Fe}$ are consistent with those of $\mathrm{Al}$ in all the sites (Fig. 1). Atmospheric $\mathrm{Al}$ has commonly been used as a ref-
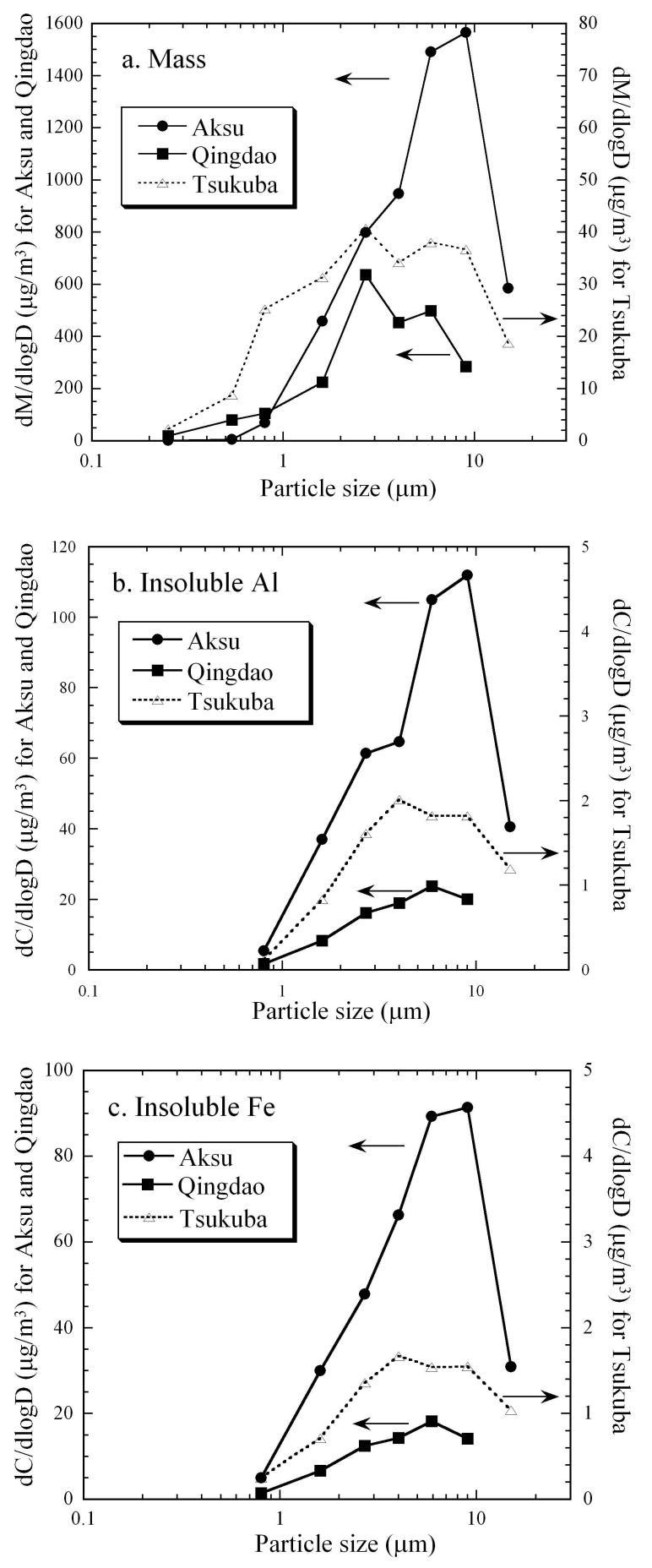

Fig. 1. Physical and chemical characteristics of aerosol samples. (a) Mass distributions of aerosols with different particle diameters. Samples were collected during the large dust event simultaneously observed in Aksu, Qingdao, and Tsukuba in March 2002. (b, c) The distributions of chemical compositions of the water-insoluble $\mathrm{Al}$ and $\mathrm{Fe}$, respectively. 

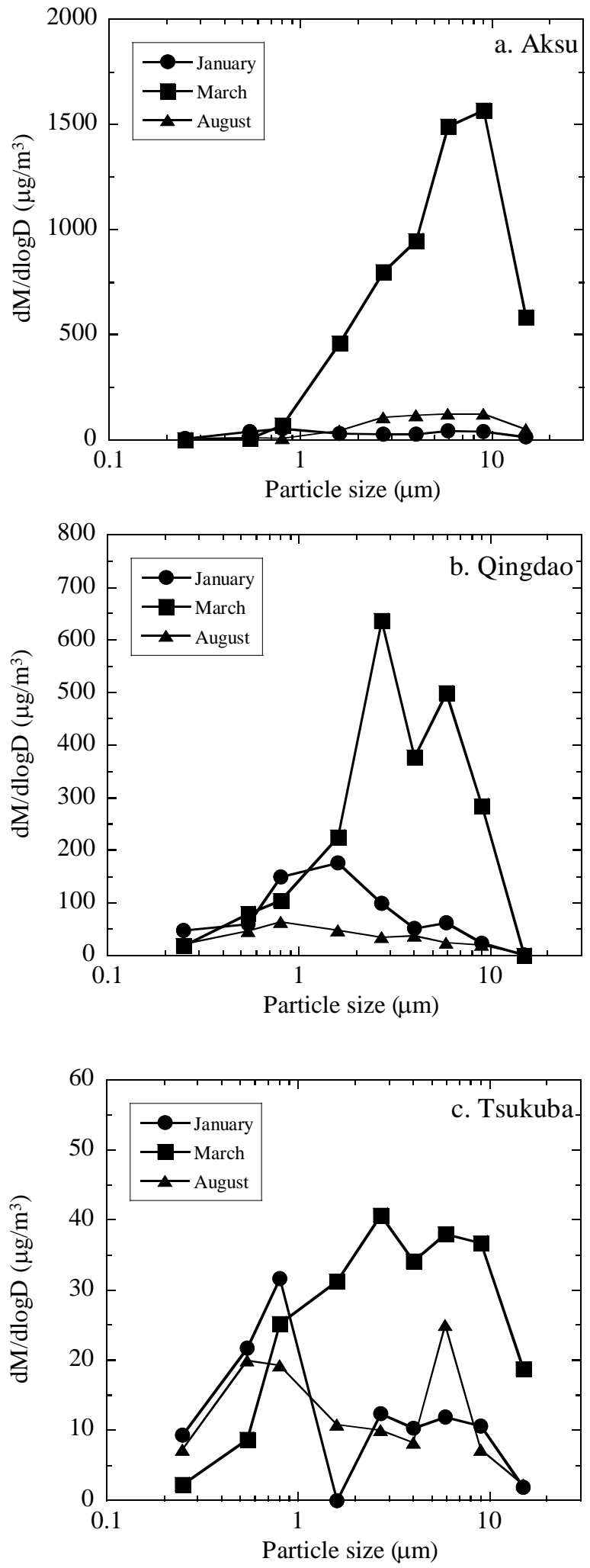

Fig. 2. Mass distributions of aerosols of various particle sizes in August 2001 (1-7 August for Aksu; 11-17 August for Qingdao; 2-21 August for Tsukuba), January 2002, and March 2002.

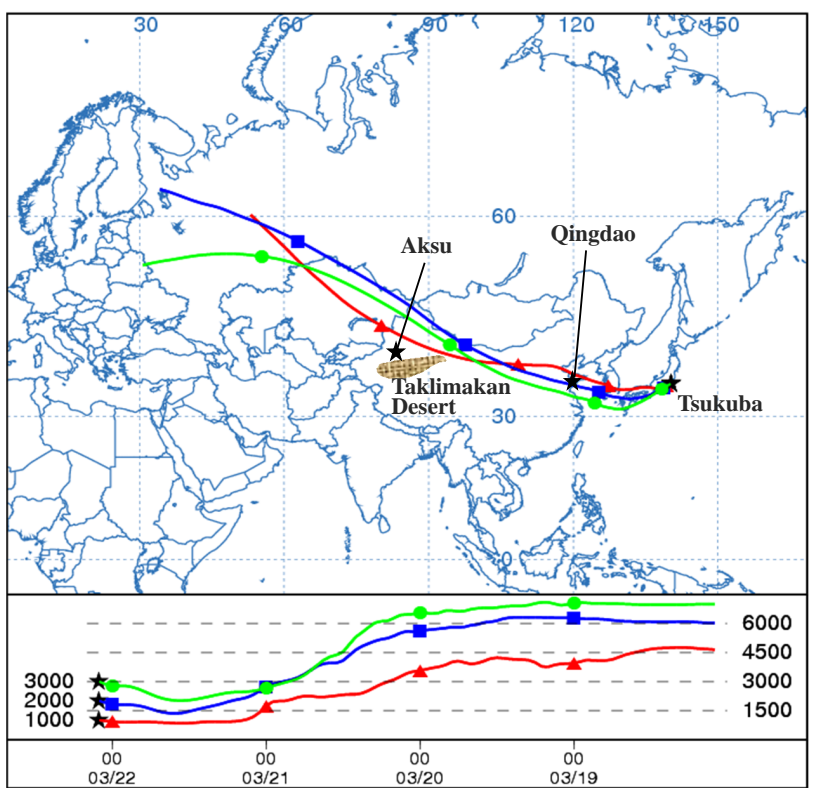

Fig. 3. Three-dimensional air mass backward trajectories during sampling periods of March 2002. The NOAA/ARL HYSPLIT model (Draxler and Rolph, 2003) was used for the calculation. The trajectories started at the altitude of $1000 \mathrm{~m}, 1500 \mathrm{~m}$, and $3000 \mathrm{~m}$ above the sampling site in Tsukuba.

erence indicator for aerosols provided from soil and crustal weathering processes because of the high Al-silicate content of the aerosols (Duce et al., 1980). Thus, a concentration ratio of $\mathrm{Fe}$ to $\mathrm{Al}$ seems to be a good signature on the regional scale, which allows us to identify the origin of the dust from different regions, or to distinguish the Asian dust in different Chinese desert source regions (Zhang et al., 1997). The $\mathrm{Fe} / \mathrm{Al}$ ratios of Aksu samples at particle size greater than $1 \mu \mathrm{m}(\mathrm{Fe} / \mathrm{Al}=0.79)$ were analogous with that of dust particles near the Taklimakan Desert $(\mathrm{Fe} / \mathrm{Al}=0.83)$, whereas different from 0.55 and 0.40 in northern desert in China and Tadzhikistan in central Asia, respectively (Zhang et al., 1997; Gomes and Gillette, 1993). Furthermore, comparison among Aksu, Qingdao, and Tsukuba samples does not show any significant differences in the ratio $(\mathrm{Fe} / \mathrm{Al}=0.79-0.85)$, showing atmospheric transport of $\mathrm{Fe}$ in the Asian dust originating from the Taklimakan Desert to east China and Japan in this period. These results also indicate that other $\mathrm{Fe}$ species are not supplied locally from terrestrial, anthropogenic, and marine sources during the long-range transport, because the elemental signature of dust particles derived from western desert sources of Asian dust is different from other sources (Zhang et al., 1997).

The anthropogenic origins of lead $(\mathrm{Pb})$ in eastern China and Japan were also determined by calculations of its enrichment factor $(\mathrm{EF})$, based on its crustal abundance relative to $\mathrm{Al}, \mathrm{EF}=(\mathrm{Pb} / \mathrm{Al})_{\text {aerosol }} /(\mathrm{Pb} / \mathrm{Al})_{\text {crust }}$. The EF values increased tenfold to a hundredfold with transport of Asian dust from 


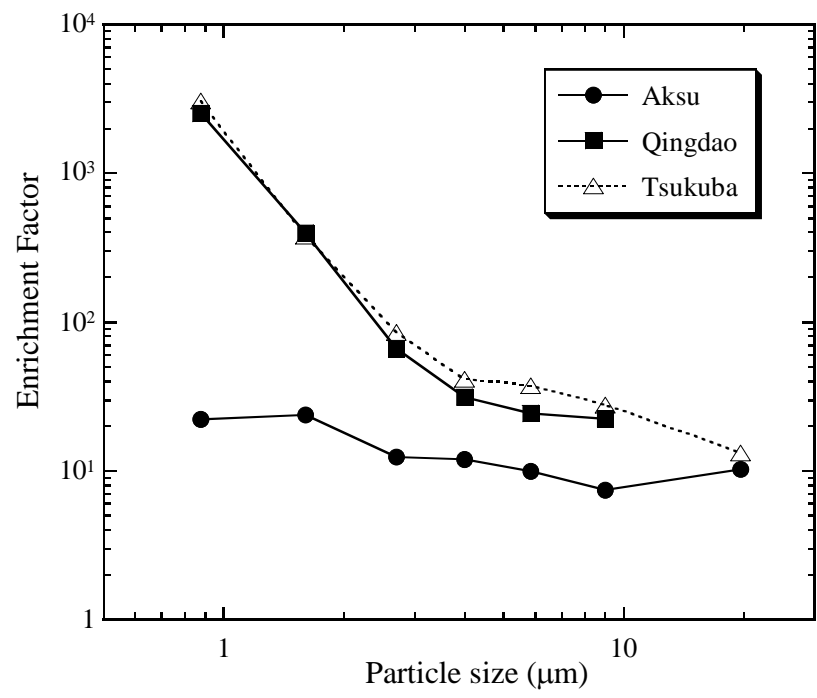

Fig. 4. Enrichment factor $(\mathrm{EF})$ for lead $(\mathrm{Pb})$ in Aksu, Qingdao, and Tsukuba. EF value was calculated y using the following equation: $\mathrm{EF}=(\mathrm{X} / \mathrm{Al})_{\text {aerosol }} /(\mathrm{X} / \mathrm{Al})_{\text {crust }}$, where $(\mathrm{X} / \mathrm{Al})_{\text {aerosol }}$ is the concentration ratio of a given element $\mathrm{X}$ to $\mathrm{Al}$ in aerosols, and $(\mathrm{X} / \mathrm{Al})_{\text {crust }}$ is the concentration ratio in the average crustal abundance (Taylor and McLennan, 1985).

western China to eastern China as seen in the data of Qingdao and Tsukuba employed here (Fig. 4), which are indicative of supply of anthropogenic lead. Thus, anthropogenic chemicals such as $\mathrm{SO}_{2}$, sulfuric acid, and $\mathrm{NO}_{\mathrm{x}}$ are expected to cause some chemical effects on the Asian dust, even for the samples rich in mineral particles. As a result, calcite originally contained in the dust collected in Aksu was transformed into gypsum during the long range transport for the same samples collected in March 2002, as shown in our previous studies on calcium $(\mathrm{Ca})$ speciation by XAFS (Takahashi et al., 2009). The pH of water contacted with the total suspended particulate (TSP) samples was 9.3 for the sample collected in Aksu, which decreased to $\mathrm{pH} 6.0$ in Tsukuba. These results showed that the dusts experienced reactions with acidic species during the transport.

\subsection{Dust mineralogy and iron speciation}

Mineralogical analyses of desert sand in the Taklimakan Desert and TSP collected at Aksu and Tsukuba provide insights into their implications on the regional aeolian processes in East Asia. Although the desert sand consists mainly of quartz, feldspar, and calcite, its XRD pattern indicates a predominance of clay minerals such as illite and chlorite in the particles less than $2 \mu \mathrm{m}$ that were separated by sedimentation in water (Fig. 5). TSP collected in Aksu was also characterized by clay minerals, quartz, and calcite. The mineralogy of PM10 collected during severe Asian dust events in 2000 and 2002 in eastern China (Shi et al., 2005) was primarily clay minerals $(>40 \%)$, followed by quartz and non-

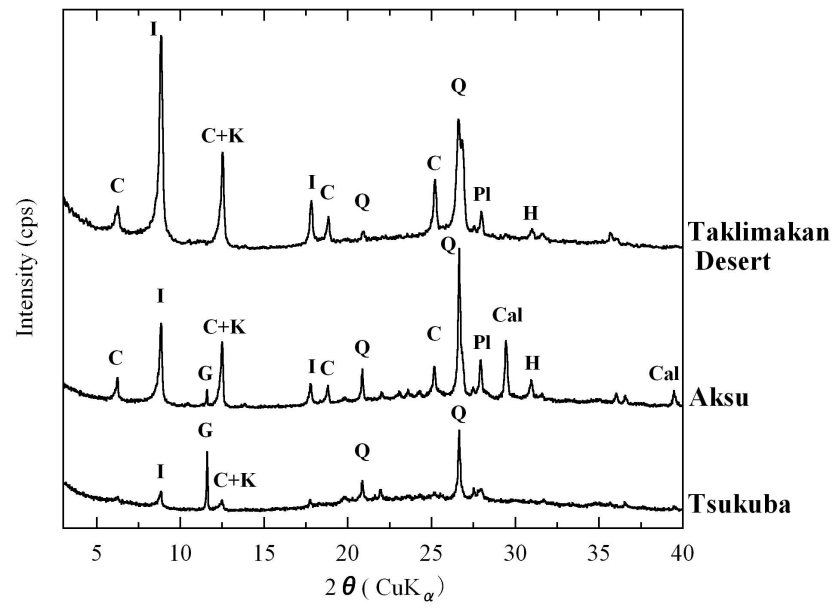

Fig. 5. X-ray diffraction patterns of the desert sand in the Taklimakan Desert and total suspended particulates (TSP) collected at Aksu and Tsukuba without filter. The desert sand less than $2 \mathrm{~mm}$ was separated from the bulk sample by sedimentation in water based on Stokes' settling law. I, illite; C, chlorite; Q, quartz; C+K, chlorite+kaolinite; $\mathrm{G}$, gypsum; $\mathrm{Pl}$, plagioclase; $\mathrm{Cal}$, calcite; $\mathrm{H}$, halite.

crystalline materials, with smaller amounts of calcite, plagioclase, K-feldspar, pyrite, and other trace minerals. Fine soil particles released by saltating sand particles and blown to high altitudes can be transported over long distances, suggesting that clays could initially be the main components of Asian dust.

Among the numerous mineralogical species that may contain iron (clays, oxides, and hydroxides), a useful mineralogical classification distinguishes three Fe categories: (i) "structural $\mathrm{Fe}$ " as $\mathrm{Fe}(\mathrm{II})$ or $\mathrm{Fe}(\mathrm{III})$ trapped in the crystal lattice of Al-silicate minerals; (ii) "crystalline $\mathrm{Fe}$ minerals" such as goethite and hematite; (iii) "non-crystalline Fe" as amorphous $\mathrm{Fe}(\mathrm{III})$ hydroxide particles, or ferrihydrite. XAFS, which consists of XANES and EXAFS, is effective in the Fe speciation, including amorphous species that cannot be identified by XRD. Variation in the XANES region at the Fe K-edge has been known to be sensitive to the local structural environment of $\mathrm{Fe}$ because of the multiple scattering of photoelectrons (Schilling et al., 1999), by which Fe species can be identified. Many past studies applied XAFS to Fe speciation in various samples and compared the results with other speciation methods such as chemical extraction, and concluded that the effectiveness of the XAFS method for $\mathrm{Fe}$ speciation (LaForce and Fendorf, 2000; Wilke et al., 2001; O'Day et al., 2004; Prietzel et al., 2007; Itai et al., 2008). For size-fractionated Aksu samples (particle size $>2.1 \mu \mathrm{m}$ ), the spectra can be perfectly fitted by a combination of those of illite, chlorite, and ferrihydrite using least-squares fitting (Fig. 6; the spectra for other reference materials are shown in Fig. S1 in the Supplement). If the scan was repeated to yield better statistics, each sample spectrum was obtained as the average of multiple runs. The results are consistent with 
(a)

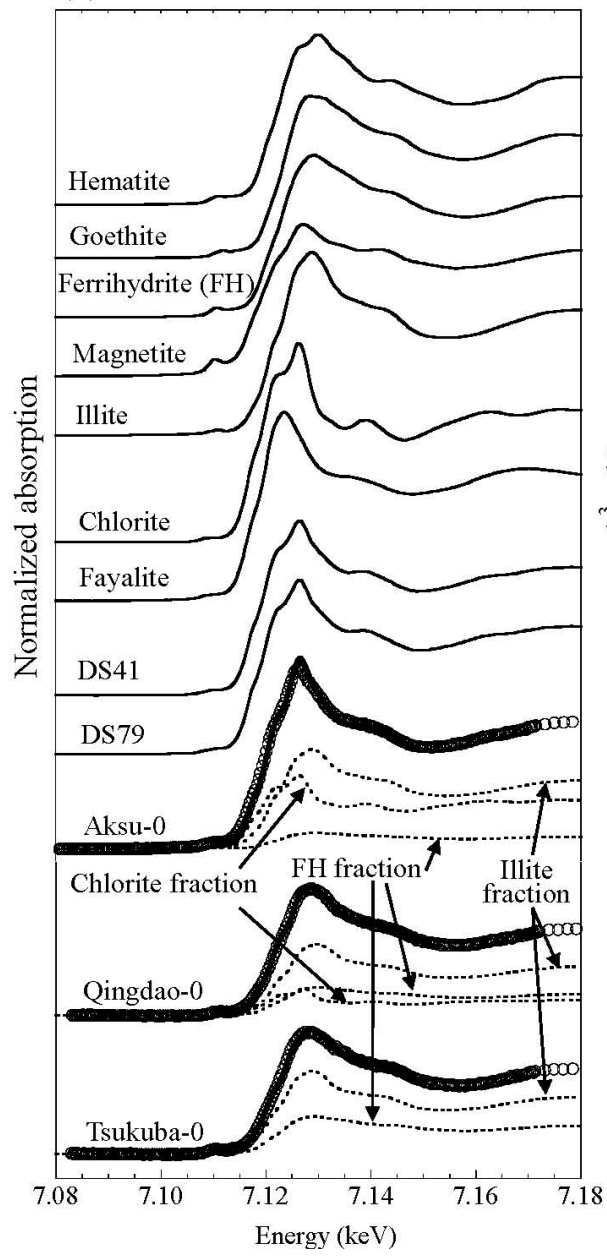

(b)

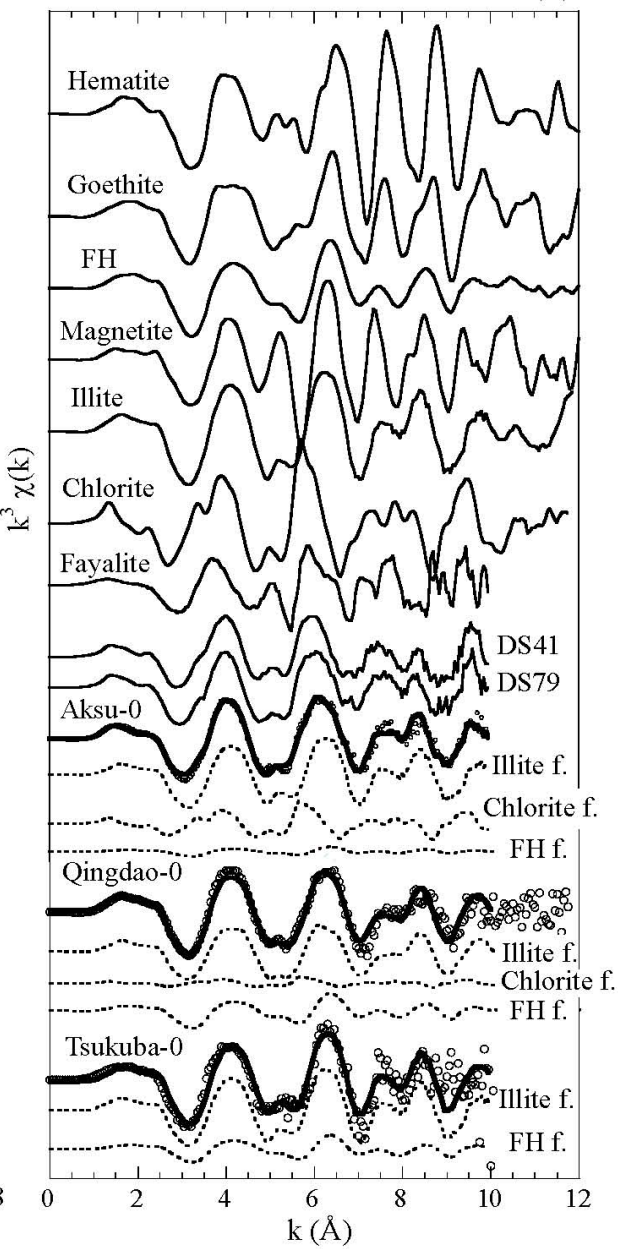

Fig. 6. Selected XAFS spectra and the results of linear combination fit (LCF). (a) Normalized Fe K-edge XANES spectra of reference materials (hematite $\left(\alpha-\mathrm{Fe}_{2} \mathrm{O}_{3}\right)$, ferrihydrite, magnetite $\left(\mathrm{Fe}_{3} \mathrm{O}_{4}\right)$, illite (IMt-1), chlorite $(\mathrm{CCa}-2)$, and fayalite $\left(\mathrm{Fe}_{2} \mathrm{SiO}_{4}\right)$ ) and some Asian dust samples (Aksu-0 and Tsukuba-0). The sample name Aksu-0, for example, denotes that the sample was at stage 0 (particle diameter $>11 \mu \mathrm{m}$ as shown in Methods) collected at Aksu. Taklimakan desert sand is obtained as shown in Chang et al. (2000). (b) Normalized $k^{3}$-weighted EXAFS spectra at Fe K-edge. Examples of the fittings of the sample spectra by LCF of illite, chlorite, and ferrihydrite (dotted lines) were also indicated for Ak-0 and Tk-0, respectively. Circles show experimental values, while the solid curve indicates the spectrum resulting from LCF.

XRD analysis of TSP samples from Aksu, which shows the presence of chlorite and illite without large peaks of other Fe minerals such as goethite and hematite for the samples studied here. It is also reasonable that ferrihydrite does not give any peaks because of its amorphous nature. The perfect consistency between XANES and XRD analyses indicates that the XANES fitting, which assumes illite and chlorite as primary Fe species in the dust, is valid. Based on linear combination fits (LCF), Fe species of the samples consist of approximately $70 \%$ illite, $20 \%$ chlorite, and $10 \%$ ferrihydrite. However, this result does not exclude the presence of other minor Fe species, when the amount relative to the total $\mathrm{Fe}$ is less than $10 \%$. Addition of one component in the fitting is justified when the $R$ value decreased by at least $10 \%$ and if its fractional contribution was above $10 \%$ (Manceau et al., 2000, 2002; Takahashi et al., 2003). The fitting results that are shown here met the criteria (Fig. S2 in the Supplement).

The systematic peak shifts in the XANES spectra among Aksu, Qingdao, and Tsukuba samples (Figs. 6a and 7) show that the ratio of $\mathrm{Fe}(\mathrm{III})$ to total $\mathrm{Fe}$ increases during atmospheric transport from the Taklimakan desert to Japan because the absorption edge shifts toward higher energy with increasing the average oxidation state of Fe. For sizefractionated Tsukuba samples, however, a large fraction (60$70 \%)$ of $\mathrm{Fe}$ was illite and the rest $(20 \sim 40 \%)$ was ferrihydrite (= amorphous Fe hydroxide; Fig. 6a). In natural samples, the combination of extremely fine grain size and poor crystallinity make ferrihydrite difficult to identify and 


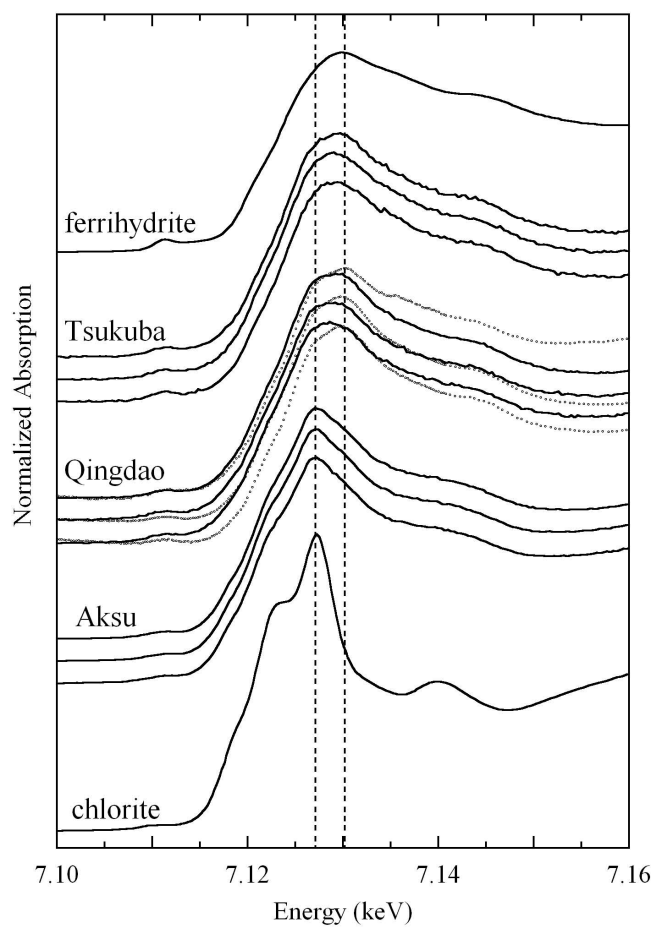

Fig. 7. Normalized Fe K-edge XANES spectra for systematicallycollected dust samples. Solid line: FY-XANES; Dotted line: CEYXANES; Dashed line: main peak position of chlorite and ferrihydrite. Note the differences in the FY- and CEY-XANES spectra for Qingdao samples and the systematic peak shift among Aksu, Qingdao, and Tsukuba, suggesting the increase of Fe(III) ratio to total Fe during the atmospheric transport from the Taklimakan Desert to Japan.

quantify by conventional techniques such as XRD. However, we could identify ferrihydrite since XAFS is sensitive to short-range structural order such as valence, coordination geometry, bond distance, and ligand coordination number (Wilke et al., 2001; O'Day et al., 2004). The $R$ values, the residual of LCF, were very low (less than $2.3 \%$ for XANES fitting) showing that the fitting can give Fe speciation data (Table S2 in the Supplement). Furthermore, a similar LCF method was employed for the $k$-space spectra of extended $\mathrm{X}$-ray absorption fine structure (EXAFS). The results of the Fe species estimated by EXAFS are very similar to those obtained by XANES in any of the samples (Fig. 6b; Table S2 in the Supplement). The EXAFS spectrum of ferrihydrite is different from those of goethite and hematite (Figs. $6 \mathrm{~b}$ and $\mathrm{S} 1$ in the Supplement), showing that the Fe (hydr)oxide species formed in the samples is mainly ferrihydrite. All the data above indicated that the Fe species in Asian dust in the source region were mainly clay minerals (+ some ferrihydrite) derived from the Taklimakan Desert, whereas the Fe species after the long-range transport (in Qingdao and Tsukuba) contained a larger amount of secondary ferrihydrite relative to the total $\mathrm{Fe}$ in the dust.
Considering the precision of the fitting procedure, the ferrihydrite fraction was estimated to be $10 \pm 5 \%$ and $24 \pm 5 \%$ of the total aerosol samples (TSP) collected in Aksu and Tsukuba, respectively. The presence of ferrihydrite in the Aksu sample is not definitive based on the XAFS method. These values were confirmed by the chemical extraction of the ferrihydrite fraction in the TSP sample using oxalate solution $(0.10 \mathrm{M})$. Consequently, $6.1 \%$ and $16 \%$ of the $\mathrm{Fe}$ were dissolved in the samples from Aksu and Tsukuba, respectively. These results are qualitatively consistent with the XANES and EXAFS data shown above, though the values in the chemical extraction can be lower than the values obtained spectroscopically, possibly due to the incomplete dissolution of ferrihydrite.

The total $\mathrm{Fe}$ oxide fractions were also estimated using the CBD method: $10 \%$ and $18 \%$ for the TSP samples in Aksu and Tsukuba, respectively. These percentages were larger than those obtained by the oxalate method, presumably caused by the presence of more crystalline Fe oxides such as goethite and hematite. However, the relative abundances of the sum of goethite and hematite were lower than $5 \%$. Such small fractions cannot be identified by XAFS method, as suggested in Manceau et al. (2002), which shows that the presence of the minor component can be considered if its fractional contribution is above $10 \%$. Thus, the Fe speciation data obtained by XAFS are essentially consistent with those determined using conventional chemical extraction methods, considering that XAFS detected the main Fe species with the fraction above $10 \%$. This is partly caused by the fitting procedure, wherein the number of $\mathrm{Fe}$ species for the fitting was limited to less than three.

The relative amounts of total Fe oxides determined by the CBD method $(=10 \%$ and $18 \%)$ in Aksu and Tsukuba, respectively, were somewhat smaller than those reported in other studies ranging from $30-60 \%$ by CBT method (Lazaro et al., 2004; Lafon et al., 2006) and $15 \%$ (Weber et al., 2000) including urban aerosols. Considering that our samples were collected during very intense dust event, most of the Fe may initially be contained in the mineral dusts from arid areas in China. Iron(III) oxides are formed during the chemical weathering of various primary minerals. Since physical weathering rather than chemical weathering is important for the formation of desert sand in the arid areas, it is possible that $\mathrm{Fe}$ (III) oxide contents cannot be high as those in the aerosols originated from soils formed under humid climate.

Further support for the fitting results was obtained through statistical data for the XANES and EXAFS fitting. Principle component analysis (PCA) in such fitting has been often used to estimate the number of end members required to fit the spectra. The PCA for all the XANES spectra for the Aksu, Qingdao, and Tsukuba samples measured both in FY and CEY modes showed that the number of independent end members can be three or four (Fig. S3 and Table S3 in the Supplement). Given that chlorite and illite are main $\mathrm{Fe}$ species in the samples collected in Aksu and Qingdao, these 


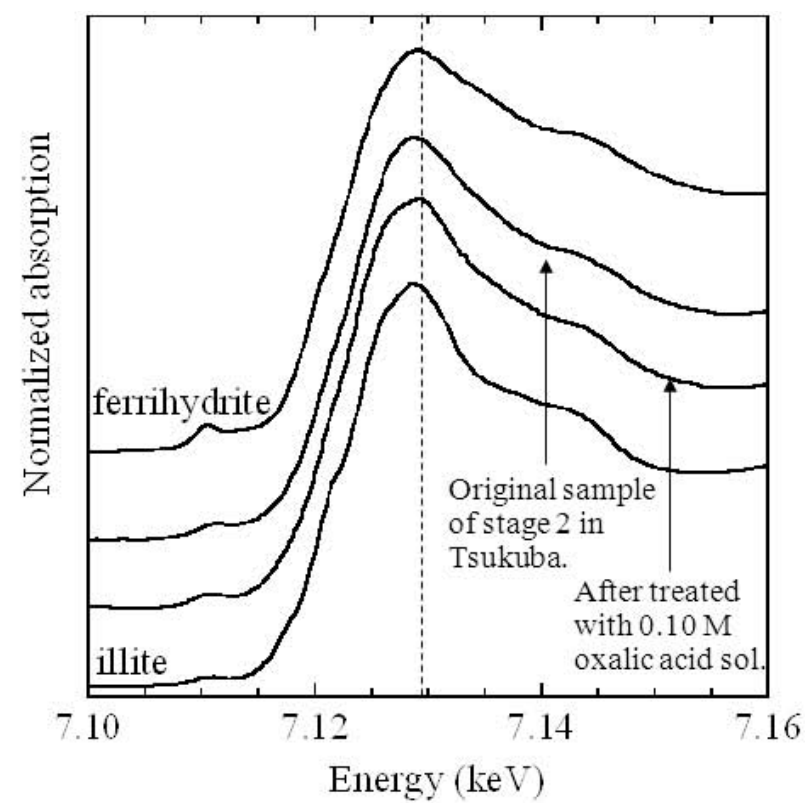

Fig. 8. Normalized Fe K-edge XANES spectra of aerosol sample collected at stage 2 in Tsukuba before and after the treatment with oxalic acid solution $(0.10 \mathrm{M})$.

two species are likely the end members of the Fe species. In addition, the Fe oxide fraction should contain ferrihydrite, goethite, and hematite as suggested by the CBD and the oxalate method. The comparison of the two leaching methods suggests that ferrihydrite is the main Fe oxide species in the samples. This is consistent with the absence of goethite and hematite in the XRD results. Thus, we decided to employ illite, chlorite, and ferrihydrite to fit all the XANES and EXAFS spectra in our samples. The fitting procedure was also shown in Fig. S2 in the Supplement, showing that the three end members can account for the spectra recorded.

Additional data to support the results were obtained from the change in the XANES spectra of $\mathrm{Fe}$ in the aerosol samples on the filter before and after the oxalate treatment (Fig. 8). The spectrum after the oxalate treatment (i.e., selective dissolution of ferrihydrite) became closer to that of illite, showing the dissolution of the ferrihydrite present before the treatment. The result also shows the reliability of the estimation of Fe species using XANES and EXAFS fitting.

\subsection{Formation of ferrihydrite on Asian dust during long-range transport}

Iron species for all the samples determined here are shown in Fig. 9. Comparing the three sites, illite was the dominant $\mathrm{Fe}$ species in the Asian dust and the ratio of illite to chlorite (I/C) increased progressively as Aksu < Qingdao < Tsukuba. There is a significant difference in the $\mathrm{I} / \mathrm{C}$ ratio of mineral dust collected at Chinese desert regions (low; Feng et al., 2002) versus at the western North Pacific (high; Leinen et al., 1994). In addition, ferrihydrite fraction to total Fe increased during the transport from western China to eastern China and Japan, although illite fraction was almost constant throughout. This fact suggests that the chemical transformation of structural $\mathrm{Fe}$ in chlorite particles into secondary ferrihydrite takes place during long-range transport of mineral dust. Contribution of any Fe species provided from the local sources near the sampling site can be negligible, as discussed before. The formation of ferrihydrite following the release of $\mathrm{Fe}$ (II) can occur as a result of the dissolution of chlorite, oxidation to $\mathrm{Fe}(\mathrm{III})$, hydrolysis, and subsequent precipitation (Zänker et al., 2006). Ferrihydrite is an important secondary Fe phase which forms coatings on mineral surfaces (Zänker et al., 2006) by the dissolution of ferrous ion, oxidation, and precipitation in water phase. The formation of ferrihydrite was also suggested by the reaction with water in aerosol such as in cloud processing (Shi et al., 2009). Chlorite dissolution rate (Brandt et al., 2003), or Si release rate in dissolution experiments at $25^{\circ} \mathrm{C}$ and $\mathrm{pH} 4$, was $5.1 \times 10^{-10} \mathrm{~mol}_{\mathrm{Si}} \mathrm{m}^{-2} \mathrm{~s}^{-1}$, much larger than illite dissolution rate (Kohler et al., 2003) of $1.0 \times 10^{-13} \mathrm{~mol}_{\mathrm{Si}} \mathrm{m}^{-2} \mathrm{~s}^{-1}$, showing that chlorite is much more reactive than illite. These results confirm that structural Fe trapped in the crystal lattice of chlorite in Asian dust can change into secondary ferrihydrite through the reactions in water layer at dust surface (Shi et al., 2009).

Large amounts of air pollutants such as $\mathrm{SO}_{2}$ and $\mathrm{NO}_{\mathrm{x}}$ are emitted in eastern China (Akimoto and Narita, 1994; Takahashi et al., 2009). Chemical speciation of Ca contained in the same dust samples used in this study revealed the neutralization processes of anthropogenic sulfur species in the atmosphere by calcite in the Asian dust. This finding was consistent with a progressive decrease in the $\mathrm{pH}$ of water equilibrated with dust samples in the order Aksu ( $\mathrm{pH}$ 9.0) $>$ Tsukuba (pH 6.0) as shown in Takahashi et al. (2009). One may think that the value of $\mathrm{pH} 6.0$ is not acidic to facilitate alteration of chlorite. However, the $\mathrm{pH}$ in Takahashi et al. (2009) was measured for $10 \mathrm{~mL}$ water in contact with about $1-5 \mathrm{mg}$ of aerosol. Since the amount of water phase at aerosol surface is very small, in situ $\mathrm{pH}$ at the aerosol surface should be much lower than that measured in Takahashi et al. (2009) as suggested in Ludwig and Klemm (1990). In addition, the $\mathrm{pH}$ value included the effect of dissolution of alkaline salts such as carbonate remaining in the aerosols into the solution, which can increase significantly the $\mathrm{pH}$ value. However, it has been suggested that Fe-rich particles are often externally mixed with carbonate (Sullivan et al., 2007) and that Fe-rich particles experience low $\mathrm{pH}$ condition during the long-range transport (Ito and Feng, 2010). Thus, it is likely that in situ $\mathrm{pH}$ condition can be low which accelerates the alteration of chlorite in the aerosol.

During the transport of Asian dust, several particles may be mixed during in-cloud processes (Desboeuf et al., 2001). Incorporation of acids to the mixed aerosols (Andreae et al., 1986) results in formation of acidic hydration layers in aerosol particles. Meskhidze et al. (2005) developed an 

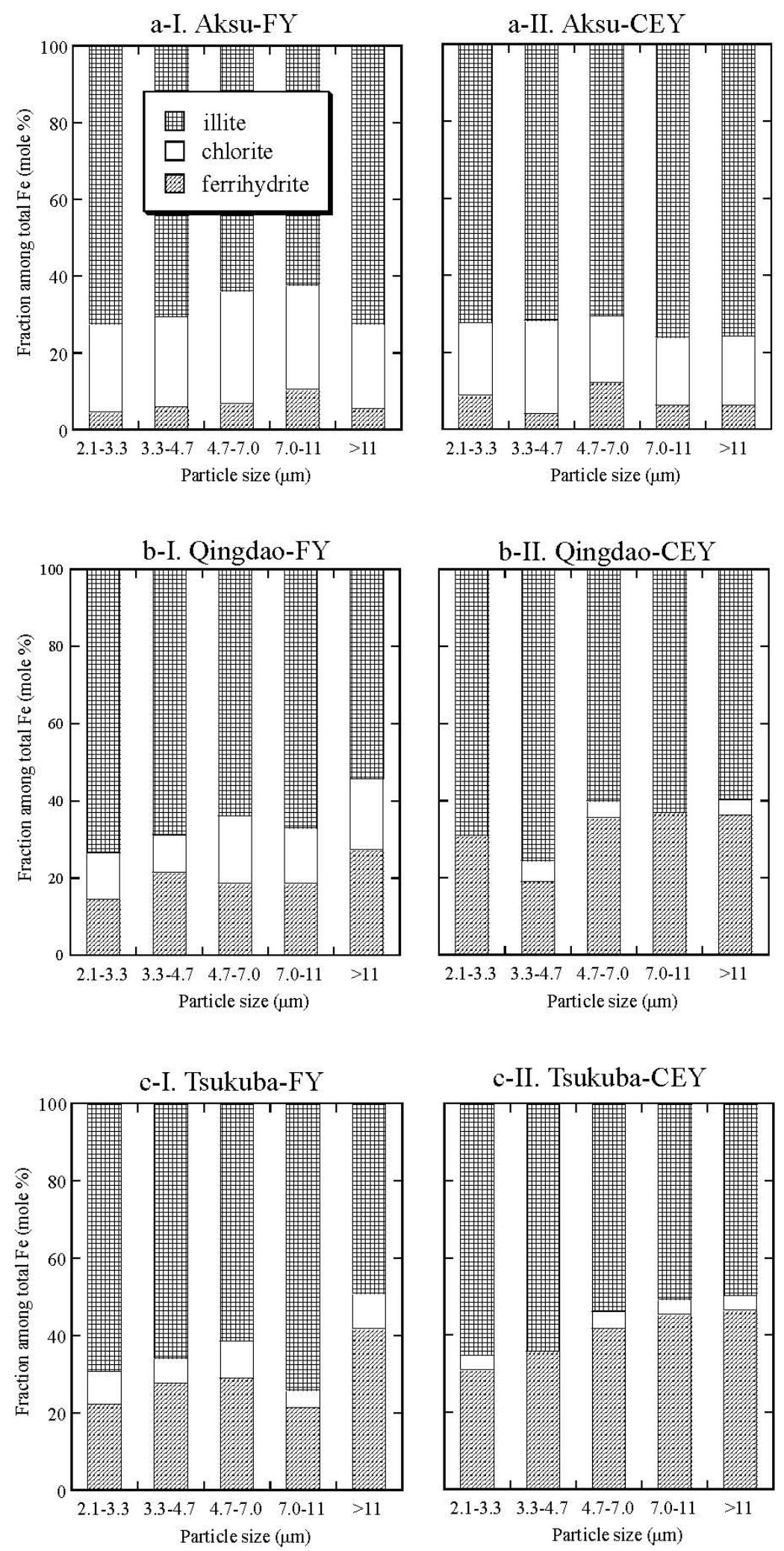

Fig. 9. Fraction of Fe species among total Fe at various particle sizes. (a)-(c) LCF results obtained in FY- and CEY-XANES in Aksu, Qingdao, and Tsukuba, respectively. 
extensive mechanism to describe the interaction of $\mathrm{Fe}$ in the dust and anthropogenic pollutants related to the eastern Asia outflow of the pollutants. Chemical reactions occurring in the water layer coating on dust particles are very important, since it regulates the $\mathrm{pH}$ of the water layer, mineral dissolution, and release of soluble Fe. The role of anthropogenic acid on the change of $\mathrm{Fe}$ species have been suggested also in other studies (e.g., Fan et al., 2006; Hsu et al., 2010).

\subsection{Comparison with the CEY-XAFS spectra}

The release of $\mathrm{Fe}(\mathrm{II})$ by the alteration of chlorite, its oxidation to $\mathrm{Fe}(\mathrm{III})$, and subsequent hydrolysis result in the formation nanoparticles of ferrihydrite (e.g., Krawczyk-Bärsch et al., 2004) as aggregates, which can be associated with other minerals in the coarser fractions $(>1 \mu \mathrm{m})$, as suggested in SEM images reported in Shi et al. (2009). SEM image similar to Shi et al. (2009) was also obtained in this study (Fig. S4), though the resolution of our apparatus is not very good. In this case, ferrihydrite can be more sensitive to surface sensitive analysis due to its small size and formation at other minerals' surfaces. Thus, XANES in conversion electron yield (CEY) mode was also employed here, since the method is sensitive to $\mathrm{Fe}$ species at surfaces less than $0.16 \mu \mathrm{m}$ (Itai et al., 2008).

The surface-sensitive CEY-XANES for size-fractionated Aksu samples gave the $\mathrm{I} / \mathrm{C}$ ratio identical to that given by XANES in FY mode (Fig. 9), showing that (i) sizes of chlorite and illite are similar in each size-fractionated sample and (ii) alternation of chlorite from the surface is minimal in Aksu. For both Qingdao and Tsukuba samples, however, CEY-XANES spectra are shifted to higher energy compared with those measured in FY mode (an example is shown by bold line for Qingdao sample in Fig. 7), reflecting the selective detection of more oxidized species by CEY-XANES. Fitting of the spectra showed that illite and ferrihydrite are predominant species in the CEY-XANES spectra without contribution of chlorite (Fig. 9).

Calcium speciation for the same samples showed that the transformation of calcite to gypsum by the reaction with sulfuric acid proceeds from the surface of the calcite (Takahashi et al., 2009). The transformation causes (i) the larger fraction of gypsum in finer particles and (ii) gypsum fraction measured in CEY mode is larger than that in FY. The latter was valid to the ferrihydrite fraction in the case of $\mathrm{Fe}$ speciation, but similar trend to the size effect shown as (i) was not obvious for ferrihydrite/chlorite nor ferrihydrite/illite ratios in this study. In contrast, the ferrihydrite fraction is almost similar among different sizes. The larger ratios of ferrihydrite in CEY mode than in fluorescence mode can be due to either (i) selective formation of ferrihydrite at the surface of the particle or (ii) finer particles sizes of ferrihydrite than other $\mathrm{Fe}$ species in the samples. If the reaction producing ferrihydrite proceeds from the chlorite surface and the ferrihydrite formed covers the chlorite surface, larger fraction of ferrihydrite is expected for the smaller particle, which was not the case for the preset results. Thus, the fact that the ferrihydrite fraction in CEY mode is larger than that in FY mode shows the smaller particle size of ferrihydrite, which is more sensitive to CEY detection than illite and chlorite. The results agreed well with the fact that ferrihydrite is formed as nanoparticles (Cornell and Schwertmann, 2003). In addition, because the samples in this study were collected by size-fractionated sampling, the present results suggested that ferrihydrite is attached to larger particles in each size fraction, as suggested in other studies (Shi et al., 2009).

\subsection{Solubilities of iron in simulated rainwater and seawater}

In this study, Fe solubilities in simulated rainwater and seawater were defined as dissolved $\mathrm{Fe}$ fractions in 24 hours using a weak acid $(0.020 \mathrm{M}$ oxalate, $\mathrm{pH} 4.7)$ and $0.70 \mathrm{M} \mathrm{NaCl}$ solution with EDTA (EDTA: $0.10 \mathrm{mM}$; pH 8), respectively (dust sample: $2.1 \mathrm{mg}$; solution volume: $15 \mathrm{~mL}$ ). Our experiments contained high levels of organic ligands with the potential to form complexes with dissolved $\mathrm{Fe}$, which can contribute to the enhancement of Fe solubility in seawater. The presence of such ligands is essential for the dissolution of $\mathrm{Fe}(\mathrm{III})$, the main Fe species in seawaters. Indeed, organic ligands (e.g., oxalate) as natural $\mathrm{Fe}$ chelators are likely to be present in rainwater and ambient aerosols (Siefert et al., 1994; Sempere and Kawamura, 1996). In seawater, it has been suggested that $\mathrm{Fe}$ (III) is dissolved as complexes with organic ligands such as siderophores. We employed EDTA to simulate the process in seawater, since the stability constants of Fe-siderophores (Witter et al., 2000; Hasegawa et al., 2004) and Fe-humic substance complexes (Takahashi et al., 1997) are similar to that of $\mathrm{Fe}(\mathrm{III})$-EDTA. In these systems, Fe-binding ligand concentrations may vary considerably over a wide range, which can primarily decide the dissolved concentration of $\mathrm{Fe}$ (III), since Fe(III) cannot be dissolved without formation of these complexes. In fact, leaching experiments using solutions with much lower concentration of EDTA (EDTA: $1.0 \mu \mathrm{M}$; pH 8) showed that dissolved concentrations of $\mathrm{Fe}$ were less than $0.2 \%$ of total $\mathrm{Fe}$ originally contained in the three reference materials (illite, chlorite, and ferrihydrite) and any samples in size-fractionated and TSP samples collected in Aksu and Tsukuba. Thus, the increase of Fe concentration in natural seawater is thought to be due to the presence of natural organic ligands. Since total concentration of $\mathrm{Fe}$ in our leaching solution is by far larger than actual total $\mathrm{Fe}$ concentration in rain water and seawater, it is necessary to use the high concentrations of oxalate and EDTA. Hence, it is possible that Fe solubility estimated in our leaching experiments can be different from "true" aerosol Fe solubility. However, the relative differences in Fe solubility in this study must reflect differences in Fe reactivities and solubilities to actual rainwater and seawater among ferrihydrite and clay minerals. 
Table 1. Solubilities of Fe in simulated rainwater and seawater.

\begin{tabular}{lllcc}
\hline & $\mathrm{TFe}(\mathrm{wt} \%)$ & $\mathrm{Pb} / \mathrm{Al}(1000)$ & $\frac{\text { rainwater* }}{\mathrm{Fe}_{\text {Sol }}(\%)}$ & $\frac{\text { seawater** }}{\mathrm{Fe}_{\text {Sol }}(\%)}$ \\
\hline ferrihydite & & & $40.0 \pm 5.3$ & $2.61 \pm 0.05$ \\
chlorite $(\mathrm{CCa}-2)^{* * * *}$ & $63.8 \pm 1.5$ & & $6.83 \pm 0.17$ & $1.91 \pm 0.12$ \\
illite (IMt-1) & $20.3 \pm 0.2$ & & $1.91 \pm 0.12$ & $0.57 \pm 0.05$ \\
Aksu TSP & $5.13 \pm 0.05$ & & $4.13 \pm 0.21$ & $0.28 \pm 0.07$ \\
Tsukuba TSP & $4.02 \pm 0.08$ & $12.0 \pm 0.1$ & $11.8 \pm 0.06$ & $1.10 \pm 0.07$ \\
\hline
\end{tabular}

The iron solubility $\left(\mathrm{Fe}_{\mathrm{Sol}}(\%)\right)$ is calculated as follows: $\mathrm{Fe}_{\mathrm{Sol}}(\%)=(\mathrm{D}-\mathrm{Fe} / \mathrm{T}-\mathrm{Fe}) \times 100$, where $\mathrm{D}-\mathrm{Fe}$ is dissolved $\mathrm{Fe}$ concentration in leaching solution at a temperature of $20{ }^{\circ} \mathrm{C}$ for

$24 \mathrm{~h}$ and T-Fe is total Fe concentration determined by acid digestion. Error ranges represent standard error based on triplicate analyses.

* Simulated by a solution containing $0.020 \mathrm{M}$ oxalic acid/ammonium oxalate at $\mathrm{pH} 4.7$.

** Simulated by $0.70 \mathrm{M} \mathrm{NaCl}(\mathrm{pH} 8)$ solution with $0.10 \mathrm{mM}$ ethylenediaminetetraacetic acid (EDTA).

*** 2-line ferrihydrite was prepared by hydrolysis of ferric nitrate at $\mathrm{pH} 7.5$ and $20 \pm 2{ }^{\circ} \mathrm{C}$ according to Schwertmann and Cornell.

**** IMt-1 and CCa-2 were received from the Source Clays Repository of the Clay Mineral Society.

Based on the Fe solubility in simulated rainwater (Table 1), Fe in ferrihydrite was more soluble than those in clay minerals (e.g., illite and chlorite). It appears that ferrihydrite which is rich in $\mathrm{Fe}$ with large surface area releases a larger amount of Fe into the solution than those from the clays. Ferrihydrite is thermodynamically metastable and chemically more reactive, and therefore more bioavailable than highly crystalline Fe phases such as hematite or goethite (Wells et al., 1983; Nodwell and Price, 2001). It is also reported that sunlight increases the lability of ferrihydrite in seawater (Wells et al., 1991).

The solubility of TSP collected in Tsukuba was threefold greater than that of TSP collected in Aksu; our XAFS results clearly showed that ferrihydrite content in the dust in Tsukuba is much larger than that in Aksu. These results suggest that ferrihydrite secondarily formed in the atmosphere can be a significant source of soluble Fe species in the North Pacific. This clearly confirms the results in several studies showing that marine or anthropogenic aerosols are more soluble than original crustal aerosols (Colin et al., 1990; Spokes et al., 1994) and that pollution from Asia can increase Fe solubility (Andreae et al., 1986; Duvall et al., 2008). Indeed, it was suggested in this study that a large amount of anthropogenic material (e.g., $\mathrm{Pb}$ ) is expected to contaminate the Asian dust, as discussed before.

The solubility of Fe in simulated seawater is low (Table 1), which is consistent with the solubility in seawater by Saharan and anthropogenic aerosols (0.05 to $2.2 \%$; Bonnet and Guieu, 2004). The much lower Fe solubility in seawater than in rainwater may be related to seawater $\mathrm{pH}$ of 8 , because the $\mathrm{Fe}(\mathrm{III})$ hydroxide solubility under alkaline condition is very low. Zhu et al. (1992) suggested that ferric ion solubility from $\mathrm{Fe}(\mathrm{III})$ hydroxide varies by a factor $10^{10}$ when the $\mathrm{pH}$ varies from 2 to 8 . Even so, ferrihydrite is also more soluble in seawater than clay minerals. Amorphous $\mathrm{Fe}$ is released slowly (within hours) from aerosol particles into seawater by complexation with natural dissolved organic ligands, whereas $\mathrm{Fe}$ trapped in Al-silicate lattice or crystalline $\mathrm{Fe}$ minerals dissolves in seawater too slowly (in months) to be detected in laboratory experiments (Wu et al., 2007). Thus, ferrihydrite can be soluble species and more importantly can be directly used by some photosynthetic algae species (Nodwell and Price, 2001). Moreover, Visser et al. (2003) showed that amorphous and nanoparticulate $\mathrm{Fe}$ in the Saharan dust correlates positively with Fe bioavailability for two diatom species.

Some previous studies only gave $\mathrm{Fe}(\mathrm{II}) / \mathrm{Fe}(\mathrm{III})$ ratio (Zhuang et al., 1992; Zhu et al., 1997; Luo et al., 2005; Majectic et al., 2007), which was used to discuss the reactions in the atmosphere and their solubilities in water. Based on more detailed $\mathrm{Fe}$ speciation and solubility experiments in this study suggest that oxidation into $\mathrm{Fe}(\mathrm{III})$ can increase the solubility of $\mathrm{Fe}$, whereas previous studies (Zhuang et al., 1992; Zhu et al., 1997) assumed that Fe(II) is much more soluble that Fe(III) species. However, Luo et al. (2005) suggested that there is not clear correlation between Fe(II) fraction and iron solubility, while Majestic et al. (2007) reported that $\mathrm{Fe}$ (III) contributed to a large fraction of soluble Fe. Our results also suggested that the oxidation of Fe(II) (mainly in chlorite) to Fe(III) as ferrihydrite can increase the Fe solubility, probably because $\mathrm{Fe}(\mathrm{II})$ in clay minerals is incorporated in the aluminosilicate structures. Thus, more information on $\mathrm{Fe}$ speciation data not limited to $\mathrm{Fe}(\mathrm{II}) / \mathrm{Fe}$ (III) ratio is needed to discuss more clearly the relationship between Fe species and $\mathrm{Fe}$ solubility in seawater.

Several studies have emphasized that in-cloud processes and photochemical processes in the atmosphere can modify Fe solubility of desert dust (Jickells and Spokes, 2001; Desboeufs et al., 2001; Hand et al., 2004). The data of Fe solubility and solid-state speciation presented here provide evidence that the increase of Fe solubility is also caused by another important factor, which is the formation of ferrihydrite by chemical transformation of $\mathrm{Fe}$ in chlorite during the long-range transport of Asian dust. This study indicates that ferrihydrite must be considered as an important $\mathrm{Fe}$ phase associated with atmospheric deposition in the North Pacific. By increasing the bioavailable $\mathrm{Fe}$ in surface seawater, it is possible that atmospheric aerosol dissolution affects 
primary productivity which in turn induces the uptake of atmospheric $\mathrm{CO}_{2}$ and the stimulation of biological DMS production (Zhuang et al., 1992; Turner et al., 1996).

\section{Conclusions}

This study focuses on the speciation of Fe in mineral dusts transported from Aksu (near Taklimakan Desert) to Qingdao (eastern China) and Tsukuba (Japan). Based on the fitting of XANES and EXAFS spectra measured in both fluorescence and electron yield modes, it was revealed that $\mathrm{Fe}$ species were changed from illite and chlorite originally contained in dusts in Aksu to illite and ferrihydrite in Qingdao and Tsukuba. The validity of the speciation by XANES and EXAFS were confirmed by X-ray diffraction and chemical extraction methods. The speciation showed that chlorite originally contained in the dusts was selectively transformed into ferrihydrite during the long-range transport from Aksu (illite : chlorite : ferrihydrite $=70: 25: 5$ as average values of $\mathrm{Fe}$ molar ratio at various particle sizes shown in Fig. 9 and Table S2) to Qingdao (illite $:$ chlorite $:$ ferrihydrite $=65: 15: 20$ ) and Tsukuba (illite : chlorite $:$ ferrihydrite $=65: 5: 25$ ) in the event we studied. The high reactivity of chlorite compared with illite has been suggested in alteration experiments of the two minerals in mineralogical studies, which supports our results. Since alteration of calcite to gypsum due to the reaction with sulfuric acid and also enrichment of $\mathrm{Pb}$ in finer particles were found in Qingdao and Tsukuba for the same samples examined here, it is suggested that the transformation of chlorite to ferrihydrite is facilitated by the anthropogenic effects. Solubility experiments showed that $\mathrm{Fe}$ in ferrihydrite (soluble $\mathrm{Fe}$ fraction $\left.\left(\mathrm{Fe}_{\mathrm{Sol}}\right): 40 \%\right)$ can be more soluble than those in illite $\left(\mathrm{Fe}_{\mathrm{Sol}}=1.9 \%\right)$ and chlorite $\left(\mathrm{Fe}_{\mathrm{Sol}}=6.8 \%\right)$. For natural samples, $\mathrm{Fe}_{\text {Sol }}$ in Tsukuba sample (main Fe host phase: illite and ferrihydrite) was $11.8 \%$ and $1.10 \%$ for synthetic rainwater and seawater, respectively, where were more soluble than those in Aksu sample (main Fe host phase: illite and chlorite; $\mathrm{Fe}_{\mathrm{Sol}}$ were $4.13 \%$ and $0.28 \%$, respectively) in our leaching experiments. The results of our observation suggested that the transformation of chlorite to ferrihdyrite in aerosols during the long-range transport can be one of important factors that can control the solubility of $\mathrm{Fe}$ in dusts to seawater.

\section{Supplement related to this article is available online at: http://www.atmos-chem-phys.net/11/11237/2011/ acp-11-11237-2011-supplement.pdf.}

Acknowledgements. We are grateful to S. Yabuki, Y. Kanai, and A. Ohta for collecting aerosol samples in the ADEC project. We thank H. Shimizu, and S. Yanaka for their contributions to summarize this manuscript. This research has been supported by a Grant-in-Aid for Scientific Research in Priority Areas "Western Pacific Air-Sea Interaction Study (W-PASS)". This work has been performed with the approval of KEK-PF (Proposal No. 2008G691, 2009G655, 2010G072, and 2011G197) and JASRI (Proposal No. 2008A1261, 2009A1170, 2010A1452, and 2011A1980). This research is a contribution to the Surface Ocean Lower Atmosphere Study (SOLAS) and a Core Project of the International Geosphere-Biosphere Program (IGBP).

Edited by: N. Mihalopoulos

\section{References}

Akimoto, H. and Narita, $\mathrm{H}$.: Distribution of $\mathrm{SO}_{2}, \mathrm{NO}_{\mathrm{x}}$ and $\mathrm{CO}_{2}$ emissions from fuel combustion and industrial activities in Asia with $1^{\circ} \times 1^{\circ}$ resolution, Atmos. Environ., 28, 213-225, 1994.

Andreae, M. O., Charlson, R. J., Bruynseels, F., Storms, H., Vangrieken, R., and Maenhaut, W.: Internal mixture of sea salt, silicates, and excess sulfate in marine aerosols, Science, 222, 1620 1623, 1986.

Baker, A. R., Jickells, T. D., Witt, M. and Linge, K. L.: Trends in the solubility of iron, aluminum, manganese and phosphorus in aerosol collected over the Atlantic Ocean, Mar. Chem, 98, 4358, 2006.

Bonnet, S. and Guieu, C.: Dissolution of atmospheric iron in seawater, Geophys. Res. Lett., 31, L03303, doi:10.1029/2003GL01842, 2004.

Boyd, P. W. and Ellwood, M. J.: The biogeochemical cycle of iron in the ocean, Nature Geosci., 3, 675-682, 2010.

Brandt, F., Bosbach, D., Krawczyk-Barsch, E., Arnold, T., and Bernhard, G.: Chlorite dissolution in the acid pH-range: A combined microscopic and macroscopic approach, Geochim. Cosmochim. Acta, 67, 1451-1461, 2003.

Chang, Q., Mishima, T., Yabuki, S., Takahashi, Y., and Shimizu, H.: $\mathrm{Sr}$ and $\mathrm{Nd}$ isotope ratios and REE abundances of moraines in the mountain areas surrounding the Taklimakan Desert, NW China, Geochem. J., 34, 407-427, 2000.

Colin, J. L., Jaffrezo, J. L., and Gros, J. M.: Solubility of major species in precipitation: factors of variation, Atmos. Environ., 24, 537-544, 1990.

de Baar, H. J. W., de Jong, J. T. M., Bakker, D. C. E., Löscher, B. M., Veth, C., Bathmann, U., and Smetacek, V.: Importance of iron for phytoplankton blooms and carbon dioxide drawdown in the Southern Ocean, Nature, 373, 412-415, 1995.

Desboeufs, K. V., Losno, R., and Colin, J. L.: Factors influencing aerosol solubility during cloud processes. Atmos. Environ, 35, 3529-3537, 2001.

Draxler, R. R. and Rolph, G. D.: HYSPLIT (HYbrid Single-Particle Lagrangian Integrated Trajectory) Model access via NOAA ARL READY Website, http://www.arl.noaa.gov/ready/hysplit4.html, NOAA Air Resources Laboratory, Silver Spring, MD, USA, 2003.

Duce, R. A. and Tindale, N. W.: Atmospheric transport of iron and its deposition in the ocean, Limnol. Oceanogr., 36, 1715-1726, 1991.

Duce, R. A., Unni, C. K., Ray, B. J., Prospero, J. M., and Merrill, J. T.: Long-range atmospheric transport of soil dust from Asia to the tropical North Pacific, Temporal variability, Science, 209, 1522-1524, 1980.

Duvall, R. M., Majestic, B. J., Shafer, M. M., Chuang, P. Y., Simoneit, B. R. T., and Schauer, J. J.: The water-soluble fraction of 
carbon, sulfur, and crustal elements in Asian aerosols and Asian soils, Atmos. Environ., 42, 5872-5884, 2008.

Fan, S.-M., Moxim, W. J., and Levy II, H.: Aeolian input of bioavailable iron to the ocean, Geophys. Res. Lett., 33, L07602, doi:10.1029/2005GL024852, 2006.

Feng, Q., Endo, K. N., and Cheng, G. D.: Dust storms in China: A case study of dust storm variation and dust characteristics, Bull. Eng. Geol. Environ., 61, 253-261, 2002.

Finlayson-Pitts, B. J. and Pitts Jr., J. N.: Chemistry of Upper and Lower Atmosphere, Academic Press, San Diego, CA, USA, 1999.

Furukawa, F. and Takahashi, Y.: Oxalate metal complexes in aerosol particles: implications for the hygroscopicity of oxalatecontaining particles, Atmos. Chem. Phys., 11, 4289-4301, doi:10.5194/acp-11-4289-2011, 2011.

Gomes, L. and Gillette, D. A.: A comparison of characteristics of aerosol from dust storms in central Asia with soil derived dust from other regions, Atmos. Environ., Part A, 27, 2539-2544, 1993.

Hand, J. L., Mahowald, N. M., Chen, Y., Siefert, R. L., Luo, C., Subramaniam, A., and Fung, I.: Estimates of atmosphericprocessed soluble iron from observations and a global mineral aerosol model: Biogeochemical implications, J. Geophys. Res., 109, D17205, doi:10.1029/2004JD004574, 2004.

Hasegawa, H., Maki, T., Asano, K., Ueda, K., and Ueda, K.: Detection of iron(III)-binding ligands originating from marine phytoplankton using cathodic stripping voltammetry, Anal. Sci., 20, 89-93, 2004.

Higashi, M. and Takahashi, Y.: Detection of S(IV) species in aerosol particles using XANES spectroscopy, Environ. Sci. Technol., 43, 7357-7363, 2009.

Hsu, S.-C., Liu, S. C., Arimoto, R., Shiah, F.-K., Gong, G.-C., Huang, Y.-T., Kao, S.-J.,Chen, J.-P., Lin, F.-J., Lin, C.-Y., Huang Jr., C., Tsai, F., and Lung, S.-C. C.: Effects of acidic processing, transport history, and dust and sea salt loadings on the dissolution of iron from Asian dust. J. Geophys. Res., 115, D19313, doi:10.1029/2009JD013442, 2010.

Itai, T., Takahashi, Y., Uruga, T., Tanida, H., and Iida, A.: Selective detection of $\mathrm{Fe}$ and $\mathrm{Mn}$ species at mineral surfaces in weathered granite by conversion electron yield X-ray absorption fine structure, Appl. Geochem., 23, 2667-2675, 2008.

Ito, A. and Feng, Y.: Role of dust alkalinity in acid mobilization of iron, Atom. Chem. Phys., 10, 9237-9250, doi:10.5194/acp-109237-2010, 2010.

Jickells, T. D., An, Z. S., Andersen, K. K., Baker A. R., Bergametti, G., Brooks, N., Cao, J. J., Boyd, P. W., Duce, R. A., Hunter, K. A., Kawahata, H., Kubilay, N., laRoche, J., Liss, P. S., Mahowald, N., Prospero, J. M., Ridgwell, A. J., Tegen, I., and Torres, R.: Global iron connections between desert dust, ocean biogeochemistry and climate, Science, 308, 67-71, 2005.

Jickells, T. D. and Spokes, L. J.: The Biogeochemistry of Iron in Seawater edited by: Turner, D. R. \& Hunter, K. A., Wiley, Chichester, UK, 85-121, 2001.

Kanai, Y., Ohta, A., Kamioka, H., Terashima, S., Matsuhisa, Y., Shimizu, H., Takahashi, Y., Kai, K., Xu, B., Hayashi, M., and Zhang, R..: Variation of concentrations and physicochemical properties of aeolian dust obtained in east China and Japan from 2001 to 2002, Bull. Geol. Surv. Jpn., 54, 251-267, 2003.

Kanai, Y., Ohta, A., Kamioka, H., Terashima, S., Imai, N., Kanai,
M., Shimizu, H., Takahashi, Y., Kai, K., Hayashi, M., Zhang, R. J., and Sheng, L. F.: Characterization of aeolian dust in east China and Japan from 2001 to 2003, J. Meteorol. Soc. Jpn., 83A, 73-106, 2005.

Kohler, S., Dufaud, F., and Oelkers, E. H.: An experimental study of illite dissolution rates as a function of $\mathrm{pH}$ from 1.4 to 12.4 and temperature from 5 to $50^{\circ} \mathrm{C}$, Geochim. Cosmochim. Acta, 67, 3583-3594, 2003.

Krawczyk-Bärscha, E., Arnold, T., Reutherb, H., Brandtc, F., Bosbachc, D., and Bernharda, G.: Formation of secondary Feoxyhydroxide phases during the dissolution of chlorite - effects on uranium sorption, Appl. Geochem., 19, 1403-1412, 2004.

LaForce, M. J. and Fendorf, S.: Solid phase iron characterization during common selective sequential extractions, Soil Sci. Soc. Am. J., 64, 1608-1615, 2000.

Leinen, M., Prospero, J. M., Arnold, E., and Blank, M.: Mineralogy of aeolian dust reaching the North Pacific Ocean. 1. Sampling and analysis, J. Geophys. Res., 99, 21017-21023, 1994.

Li, Z. and Aneja, V. P.: Regional analysis of cloud chemistry at high elevations in the eastern United States, Atmos. Environ., 26, 2001-2017, 1992.

Ludwig, J. and Klemm, O.: Acidity of size-fractionated aerosol particles. Water, Air, Soil, Pollution, 49, 35-50, 1990.

Luo, C., Mahowald, N. M., Meskhidze, N., Chen, Y., Siefert, R. L., Baker, A. R., and Johansen, A. M.: Estimation of iron solubility from observations and a global aerosol model, J. Geophys. Res., 110, D23307, doi:10.1029/2005JD006059, 2005.

Majestic, B. J., Schauer, J. J., and Shafer, M. M.: Application of synchrotron radiation for measurement of iron red-ox speciation in atmospherically processed aerosols. Atmos. Chem. Phys., 7, 2475-2487, doi:10.5194/acp-7-2475-2007, 2007.

Manceau, A., Lanson, B., Schlegel, M. L., Harge, J. C., Musso, M., Eybert-Berard, L., Hazemann, J.-L., Chateigner, D., and Lamble, G. M.: Quantitative $\mathrm{Zn}$ speciation in smelter-comtaminated soils by EXAFS spectroscopy, Am. J. Sci., 300, 289-343, 2000.

Manceau, A., Marcus, M. A., and Tamura, N.: Quantitative speciation of heavy metals in soils and sediments by synchrotron X-ray techniaues, Rev. Mineral. Geochem., 49, 341-428, 2002.

Mahowald, N. M.: The atmospheric global dust cycle and iron inputs to the ocean, Global Biogeochem. Cy., 19, GB4025, doi:10.1029/2004GB002402, 2005.

Martin, J. H. and Fitzwater, S. E.: Iron deficiency limits phytoplankton growth in the north-east Pacific subarctic, Nature, 331, 341-343, 1988.

Meskhidze, N., Chameides, W. L., and Nenes, A.: Dust and pollution: a recipe for enhanced ocean fertilization?, J. Geophys. Res., 110, D03301, doi:10.1029/2004JD00508, 2005.

Meskhidze, N., Chameides, W. L., Nenes, A., and Chen, G.: Iron mobilization in mineral dust: Can anthropogenic $\mathrm{SO}_{2}$ emissions affect ocean productivity?, Geophys. Res. Lett., 30, 2085, doi:10.1029/2003GL018035, 2003.

Mikamia, M., Shi, G. Y., Uno, I., Yabuki, S., Iwasaka, Y., Yasui, M., Aoki, T., Tanaka, T. Y., Kurosaki, Y., Masuda, K., Uchiyama, A., Matsuki, A., Sakai, T., Takemii, T., Nakawo, M., Seino, N., Ishizuka, M., Satake, S., Fujita, K., Hara, Y., Kai, K., Kanayama, S., Hayashi, M., Du, M., Kanai, Y., Yamada, Y., Zhang, X. Y., Shen, Z., Zhou, H., Abe, O., Nagai, T., Tsutsumi, Y., Chiba, M., and Suzuki, J.: Aeolian dust experiment on climate impact: An overview of Japan-China joint project ADEC, Global Planet. 
Change, 52, 142-172, 2006.

Nodwell, L. M. and Price, N. M.: Direct use of inorganic colloidal iron by marine mixotrophic phytoplankton, Limnol. Oceaogr., 46, 765-777, 2001.

O'Day, P. A., Rivera, N., Root, R., and Carroll, S. A.: X-ray absorption spectroscopic study of Fe reference compounds for the analysis of natural sediments, Am. Mineral., 89, 572-585, 2004.

Prietzel, J., Thieme, J., Eusterhues, K., and Eichert, D.: Iron speciation in soils and soil aggregates by synchrotron-based X-ray microspectroscopy (XANES, $\mu$-XANES), Eur. J. Soil Sci., 58, 1027-1041, 2007.

Ravel, B. and Newville, M.: ATHENA, ARTEMIS, HEPHAESTUS: data analysis for X-ray absorption spectroscopy using IFEFFIT, J. Synchrotron Rad., 12, 537-541, 2005.

Schroth, A. W., Crusius, J., Sholkovitz, E. R., and Bostick, B. C.: Iron solubility driven by speciation in dust sources to the ocean, Nature Geosci., 2, 337-340, 2009.

Schilling, P. J., He, J. H., Tittsworth, R. C., and Ma, E.: Two-phase coexistence region in mechanically alloyed $\mathrm{Cu}-\mathrm{Fe}$ : an $\mathrm{X}$-ray $\mathrm{Ab}$ sorption Near-edge structure study, Acta Mat., 47, 2525-2537, 1999.

Schroeder, S. L. M.: Towards a 'universal curve' for total electronyield XAS, Solid State Commun., 98, 405-409, 1996.

Schwertmann, U. and Cornell, R. M.: Iron Oxides in the Laboratory, Preparation and Characterization, John Wiley \& Sons, Weinheim, Germany, 2000.

Sempere, R. and Kawamura, K.: Low Molecular Weight Dicarboxylic Acids and Related Polar Compounds in the remote marine Rain Samples collected from Western Pacific, Atmos. Environ., 30, 1609-1619, 1996.

Shao, Y. P., Yang, Y., Wang, J. J., Song, Z. X., Leslie, L. M., Dong, C. H., Zhang, Z. H., Lin, Z. H., Kanai, Y., Yabuki, S., and Chun, Y. S.: Northeast Asian dust storms: Real-time numerical prediction and validation, J. Geophys. Res., 108, 4691, doi:10.1029/2003JD003667, 2003.

Shi, Z., Shao, L., Jones, T. P., and Lu, S.: Microscopy and mineralogy of airborne particles collected during severe dust storm episodes in Beijing, China, J. Geophys. Res., 110, D01303, doi:10.1029/2004JD005073, 2005.

Shi, Z. B., Krom, M. D., Bonneville, S., Baker, A. R., Jickells, T. D., and Benning, L. G.: Formation of iron nanoparticles and increase in iron reactivity in mineral dust during simulated cloud processing, Environ. Sci. Technol., 43, 6592-6596, 2009.

Siefert, R. L., Pehkonen, S. O., Erel, Y., and Hoffmann, M. R.: Iron photochemistry of aqueous suspensions of ambient aerosol with added organic acids, Geochim. Cosmochim. Acta, 58, 32713279, 1994.

Spokes, L. J., Jickells, T. D., and Lim, B.: Solubilisation of aerosol metals by cloud processing: A laboratory study, Geochim. Cosmochim. Acta, 58, 3281-3287, 1994.

Sullivan, R. C., Guazzotti, S. A., Sodeman, D. A., and Prather, K. A.: Direct observations of the atmospheric processing of Asian mineral dust, Atmos. Chem. Phys., 7, 1213-1236, doi:10.5194/acp-7-1213-2007, 2007.

Takahashi, Y., Minai, Y., Ambe, S., Makide, Y., Ambe, F., and Tominaga, T.: Simultaneous determination of stability constants of humate complexes with various metal ions using multitracer technique, Sci. Total Environ., 198, 61-71, 1997.

Takahashi, Y., Ohtaku, N., Mitsunobu, S., Yuita, K., and Nomura,
M.: Determination of the $\operatorname{As}(\mathrm{III}) / \mathrm{As}(\mathrm{V})$ ratio in soil by $\mathrm{X}$-ray absorption near-edge structure (XANES) and its application to Arsenic distribution between soil and water, Anal. Sci., 19, 891896, 2003.

Takahashi, Y., Kanai, Y., Kamioka, H., Ohta, A., Maruyama, H., Song, Z., and Shimizu, H.: Speciation of sulfate in sizefractionated aerosol particles using sulfur K-edge X-ray absorption near-edge structure (XANES), Environ. Sci. Technol, 40, 5052-5057, 2006.

Takahashi, Y., Miyoshi, T., Higashi, M., Kamioka, H. and Kanai, Y.: Neutralization of Calcite in Mineral Aerosols by Acidic Sulfur Species Collected in China and Japan Studied by Ca K-edge Xray Absorption Near-Edge Structure. Environ. Sci. Technol., 43, 6535-6540, 2009.

Taylor, S. R. and McLennan, S. M. The Continental Crust: its Composition and Evolution, Blackwell, Oxford, 312-312, 1985.

Tessier, A., Campbell, P. C. B., and Bisson, M.: Sequential extraction procedure for the speciation of particulate trace metals, Anal. Chem., 51, 844-850, 1979.

Turner, S. M., Nightingale, P. D., Spokes, L. J., Liddicoat, M. I., and Liss, P. S.: Increased dimethyl sulphide concentrations in seawater from in situ iron enrichment, Nature, 383, 513-517, 1996.

Visser, F., Gerringa, L. J. A., Van der Gaast, S. J., de Baar, H. J. W., and Timmermans, K. R.: The role of the reactivity and content of iron of aerosol dust on growth rates of two Antarctic diatom species, J. Phycol., 39, 1085-1094, 2003.

Wells, M. L., Mayer, L. M., Donard, O. F. X., de Souza Sierra, M. M., and Ackleson, S.: The photolysis of colloidal iron in the oceans, Nature, 353, 248-250, 1991.

Wells, M. L., Zorkin, N. G., and Lewis, A. G.: The role of colloid chemistry in providing a source of iron to phytoplankton, J. Mar. Res., 41, 731-746, 1983.

Wilke, M., Farges, F., Petit, P. E., Brown, G. E., and Martin, F. Oxidation state and coordination of $\mathrm{Fe}$ in minerals: an $\mathrm{Fe} \mathrm{K}$ XANES spectroscopic study, Am. Mineral., 86, 714-730, 2001.

Witter, A. E., Hutchins, D. A., Butler, A., and Luther, G. W.: Determination of conditional stability constants and kinetic constants for strong model Fe-binding ligands in seawater. Mar. Chem., 69, $1-17,2000$.

Wu, J., Rember, R., and Cahill, C.: Dissolution of aerosol iron in the surface waters of the North Pacific and North Atlantic oceans as determined by a semicontinuous flowthrough reactor method, Global Biogeochem. Cy., 21, GB4010, doi:10.1029/2006GB002851, 2007.

Yabuki, S., Mikami, M,. Nakamura, Y., Kanayama, S., Fu, F. F., Liu, M. Z., and Zhou, H.: The characteristics of atmospheric aerosol at Aksu, an Asian dust-source region of north-west China: A summary of observations over the three years from March 2001 to April 2004, J. Meteorol. Soc. Jpn., 83A, 45-72, 2005.

Zänker, H., Hütting, G., Arnold, T., and Nitsche, H.: Formation of iron-containing colloids by the weathering of phyllite, Aquat. Geochem., 12, 299-325, 2006.

Zhang, X. Y., Arimoto, R., and An, Z. S.: Dust emission from Chinese desert sources linked to variations in atmospheric circulation, J. Geophys. Res., 102, 28041-28047, 1997.

Zhu, X., Prospero, L. M., Millero, F. J., Savoie, D. L., and Brass, G. W.: The solubility of ferric ion in marine mineral aerosol solutions at ambient relative humidities, Mar. Chem., 38, 91-107, 
1992.

Zhu, X. R., Prospero, J. M., and Millero, F. J.: Diel variability of soluble $\mathrm{Fe}(\mathrm{II})$ and soluble total Fe in North African dust in the trade wnds at Barbados, J. Geophys. Res., 102, 21297-21305, 1997.
Zhuang, G., Yi, Z., Duce, R. A., and Brown, P. R.: Link between iron an sulfur suggested by the detection of $\mathrm{Fe}$ (II) in remote marine aerosols, Nature, 355, 537-539, 1992. 